\title{
The role of a pediatric tertiary care center in avoiding collateral damage for children with acute appendicitis during the COVID-19 outbreak
}

\author{
Louise Montalva ${ }^{1}$ - Aurore Haffreingue ${ }^{1} \cdot$ Liza Ali $^{1} \cdot$ Simon Clariot $^{2} \cdot$ Florence Julien-Marsollier $^{3}$. \\ Alaa El Ghoneimi ${ }^{1,4}$. Matthieu Peycelon ${ }^{1,4}$. Arnaud Bonnard ${ }^{1,4}$
}

Accepted: 6 October 2020 / Published online: 18 October 2020

(c) Springer-Verlag GmbH Germany, part of Springer Nature 2020

\begin{abstract}
Purpose To evaluate the impact of the COVID-19 pandemic-related lockdown on management and outcomes of children with acute appendicitis.

Methods A retrospective cohort study was conducted, including children treated for acute appendicitis (January 20th-May 11th, 2020). The data regarding the severity of appendicitis and outcome were collected and compared for two time periods, before and after the nationwide lockdown (March 17th, 2020).

Results The number of cases of acute appendicitis increased by $77 \%$ during the lockdown ( $n=39$ vs. $n=69, p=0.03$ ). During the lockdown, children treated for appendicitis were older ( 11.1 vs. 8.9 years, $p=0.003$ ), and were more likely to live more than $5 \mathrm{~km}$ away from our institution $(77 \%$ vs. $52 \%, p=0.017)$. Less children had previously consulted a general practitioner $(15 \%$ vs. $33 \%, p=0.028)$, whereas more children were transferred from other hospitals ( $52 \%$ vs. $31 \%, p=0.043)$. There was no difference in terms of length of hospital stay, rate of postoperative intra-abdominal abscess, ER visits, and readmissions between both periods. Three children (4\%) were diagnosed with COVID-19 and appendicitis.

Conclusions Despite an increase in the number of children with appendicitis managed at our hospital during the COVID19-related lockdown, management, and outcome remained similar. Although our pediatric center was strongly affected by this pandemic, maintaining our prior practice strategies for acute appendicitis avoided the occurrence of collateral damage for those children.
\end{abstract}

Keywords SARS-cov- $2 \cdot$ Peritonitis $\cdot$ Pediatric surgery $\cdot$ Laparoscopy $\cdot$ Appendectomy

\section{Introduction}

Arnaud Bonnard

arnaud.bonnard@aphp.fr

1 Department of General Pediatric Surgery and Urology, Robert-Debré University Hospital, Assistance PubliqueHôpitaux de Paris (AP-HP), 48 boulevard Sérurier, 75019 Paris, France

2 Department of Anesthesia and Intensive Care, Henri-Mondor University Hospital, Assistance Publique Hôpitaux de Paris (AP-HP), Créteil, France

3 Department of Anesthesia and Intensive Care, Robert-Debré University Hospital, Assistance Publique-Hôpitaux de Paris (AP-HP), Paris, France

4 University of Paris, Paris, France
After the first cases of severe acute respiratory syndrome coronavirus 2 (SARS-CoV-2) in December 2019 in China, COVID-19 rapidly evolved towards a pandemic, requiring complete restructuring of healthcare systems worldwide [1]. With more than 6000 cases of COVID-19 diagnosed between March 1st and March 15th, France was one of the first European countries to be strongly affected by the pandemic [2]. The French government announced a series of widespread containment measures to take place on March 17th, 2020, ordering an 8-week nationwide lockdown, including closing all 'non-essential businesses and shops' and urging residents to remain home [2,3]. To deal with the exponential increase in the number of patients requiring hospitalization for moderate or severe forms of COVID-19 and the shortage in medical equipment, many hospitals in France 
were restructured to focus on management of patients with COVID-19. As such, most surgical departments cancelled all non-urgent elective surgeries, and some pediatric surgery departments closed entirely, resulting in a decrease in the number of centers performing surgeries in children $[4,5]$.

With around 100,000 consultations at the emergency department every year, our institution is the largest pediatric hospital in France [6]. Although children seem to develop milder forms of COVID-19, our institution was also affected by this crisis, as it was restructured in order to allocate a 20-bed intensive care unit (ICU) and 20 non-ICU beds for COVID-19-positive adults. Although many elective pediatric surgeries were cancelled, we provided a permanent surgical activity for pediatric surgical emergencies.

Acute appendicitis is the most common surgical emergency in children, and may present under several forms, such as uncomplicated appendicitis, or complicated appendicitis with either peritonitis or with appendiceal mass/abscess [7]. Although the cause for appendicitis remains poorly understood, we hypothesized that the COVID-19 outbreak may influence our practice regarding number of cases, management, and outcome of acute appendicitis for several reasons [8]. First of all, as most general pediatric surgery departments closed, only referral pediatric centers remained functional, and with more than 3 million children in the region of Paris, the number of patients referred to our center for appendicitis treatment may increase [9]. Secondly, the lockdown ordered by the government may discourage parents in taking their child to the hospital, possibly resulting in delayed surgical management [10]. Moreover, it has been reported that COVID-19 infection may present predominantly with gastrointestinal symptoms in children, possibly resulting in misdiagnosed appendicitis [11-13]. Finally, appendicitis may be triggered in children by viral pathogens, possibly increasing the number of patients undergoing appendectomy [14].

The aim of this study was to evaluate the impact of the COVID-19 pandemic and related lockdown on number of cases, management, and outcomes of children treated for acute appendicitis in a pediatric tertiary care center.

\section{Methods}

Medical charts of all children treated for appendicitis at our institution between January 20th, 2020 and May 11th, 2020 were retrospectively reviewed. Collected data included patients' demographics, type and duration of symptoms, previous medical consultation or transfer from another center, biological and/or radiological findings, operative or conservative management, time to appendectomy (defined as the delay between time at emergency room arrival and surgery), duration of hospital stay, outcomes, complications, such as intra-abdominal abscess (IAA), emergency room (ER) visit, and readmission rates within 30-day after discharge.

In our center, appendicitis is diagnosed upon physical examination and laboratory tests. An abdominal ultrasound may be performed with a history of abdominal symptoms for more than 3 days, appendix mass/abscess suspicion, or when the diagnosis is uncertain.

After this initial assessment in the ER, the surgeon establishes the diagnosis of appendicitis and decides on the indication of appendectomy.

Management of acute appendicitis is protocolized as followed:

- If the child presents signs of uncomplicated appendicitis and is eligible for ambulatory management (abdominal pain localized in the right lower quadrant for less than 3 days, temperature $<38^{\circ} \mathrm{C}$, absence of tachycardia, and age $>5$ years), laparoscopic appendectomy is indicated, followed by the same-day discharge if possible. Surgery is not performed during night hours for uncomplicated appendicitis. In order to promote ambulatory management of uncomplicated appendicitis, children diagnosed outside day hours with uncomplicated appendicitis may receive a single dose of oral antibiotics (amoxicillin/clavulanic acid at the dose of $100 \mathrm{mg} / \mathrm{kg}$ with a maximum of $2 \mathrm{~g}$ ) before being discharged home and readmitted the next day for surgery.

- If the child presents signs of complicated/perforated appendicitis with peritonitis (temperature $>38{ }^{\circ} \mathrm{C}$, diffuse abdominal pain, tachycardia), urgent laparoscopic appendectomy is indicated (within 4-6 h), associated with peritoneal irrigation, and suction without drainage. Surgery is followed by an initial duration of 3-5 days of antibiotics (cefotaxime $100 \mathrm{mg} / \mathrm{kg} /$ day and metronidazole $30 \mathrm{mg} / \mathrm{kg} /$ day), depending on the extent of infection.

- If the child presents signs of complicated appendicitis with appendix mass/abscess (abdominal pain $>3$ days), confirmed upon ultrasound and in the absence of signs of peritonitis, the treatment is conservative (nonoperative). Conservative treatment involves intravenous antibiotics for at least five days (cefotaxime $100 \mathrm{mg} / \mathrm{kg} /$ day and metronidazole $30 \mathrm{mg} / \mathrm{kg} /$ day), associated with abscess drainage when possible [15]. Depending on the clinical and biological course, the child may be discharged home after 5 days of antibiotics. An interval laparoscopic appendectomy would then be performed as a day-case surgery at least six weeks later.

According to our protocol, appendectomy is performed laparoscopically with three trocars. Since the beginning of the COVID-19 outbreak, we have implemented precautions regarding laparoscopy, in order to avoid healthcare professional exposure during intubation and extubation, 
but also during laparoscopy, once the pneumoperitoneum has been created. For intubation and extubation, recently published guidelines were followed by the pediatric anesthesiology team, including the use of protective personal equipment (PPE), rapid sequence induction [16-18]. Regarding laparoscopy, care was taken during surgery not to release any pneumoperitoneum, that was safely evacuated via a closed suction system before trocar removal and appendix extraction.

If a child was suspected or known to be infected with SARS-CoV-2, a nose swab specimen was collected for detection of viral nucleic acid by RT-PCR. Specific precautions were taken in the operating room (OR) when managing these patients, such as the use of PPE, the use of anteroom, and an OR runner whose role is to provide any additional drugs or equipment from outside the OR to the anteroom. The patient was then extubated in the OR and transferred to a COVID-19 ward, according to published guidelines [16-19]. The OR room is then thoroughly decontaminated. The number of personnel in contact with a COVID-19 patient was initially limited to the strict minimum required, by excluding students and residents from the OR for these cases. Surgical residents were progressively trained to effectively decrease their risk of exposure, as their reintegration in the surgical team was necessary, both for their role as a surgeon and for their training. Moreover, starting on April 17th, 2020, all patients that were to undergo a surgery or admitted to the hospital were systematically tested for SARS-CoV-2.

We compared two time periods: 8 weeks before the nationwide lockdown (January 20th, 2020 to March 16th, 2020) and 8 weeks during the nationwide lockdown (March 17th, 2020 to May 11th, 2020).

\section{Ethical approval}

This study received approval from the institutional ethical committee (CEER $\left.n^{\circ} 2,020,499\right)$ and was registered with the CNIL (the French Data Protection Authority) under the number 2217757.

\section{Statistical analysis}

Statistical analysis was performed using GraphPad Prism, version 8.4 (GraphPad software, La Jolla, CA, USA). Comparisons between groups were performed using contingency tables for categorical variables (Chi-square test for trends) and Kruskal-Wallis with Dunn's post test for continuous variables. The data were expressed as median and interquartile range (IQR). Statistical significance was defined as a $p$ value $<0.05$.

\section{Results}

Between January 20th, 2020 and May 11th, 2020, 108 children were treated for acute appendicitis at our institution (Fig. 1). There was a $77 \%$ increase in the number of cases after the nationwide lockdown, $n=39$ before the lockdown and $n=69$ during the lockdown ( $p=0.03$ ).

\section{Study population}

Children treated for acute appendicitis were older (11.1 years of age) during the lockdown as compared to before ( 8.9 years of age, $p=0.003$ ) (Table 1). Accordingly, the median weight was higher during the lockdown $(37.5 \mathrm{~kg})$ as compared to before $(28 \mathrm{~kg}, p=0.007)$. Before the lockdown, $52 \%(n=15)$ of the children lived more than $5 \mathrm{~km}$ away from Robert-Debré University Children Hospital, whereas this rate increased to $77 \%(n=53, p=0.017)$ during the lockdown.

During the lockdown, children were less likely to have previously consulted a general practitioner before coming to the emergency room as compared to before the lockdown $(15 \%$ vs. $33 \%, p=0.028)$. Moreover, there was an increase in the number of children transferred from other hospitals during the lockdown (52\% vs $31 \%, p=0.043)$.

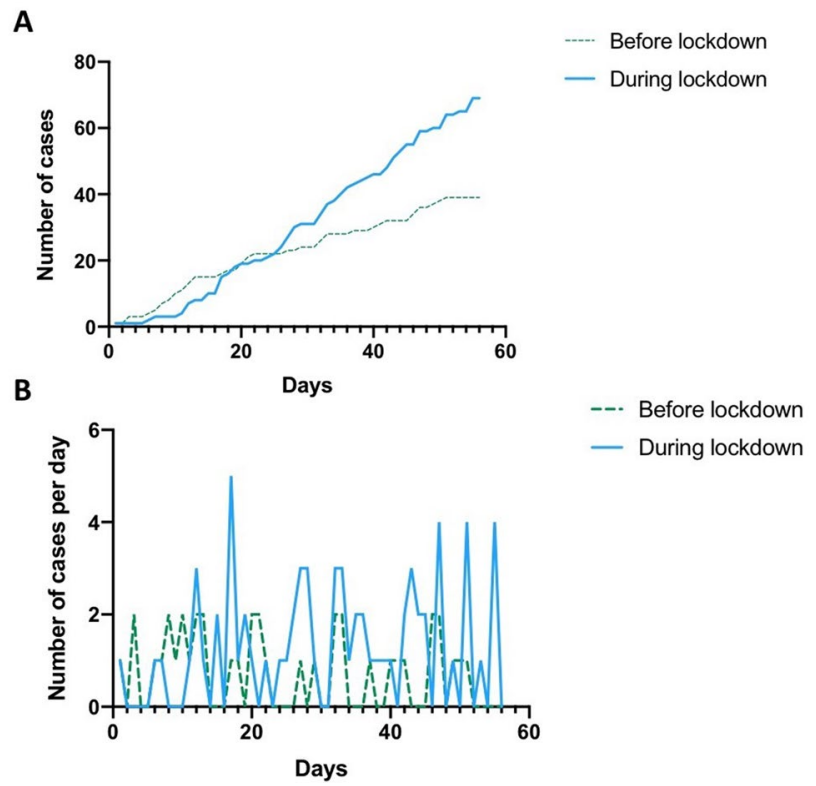

Fig. 1 Number of children treated for appendicitis, before and after national lockdown (March 17th, 2020). a Throughout the 8-week period, b Per day 
Table 1 Baseline characteristics of included patients

\begin{tabular}{llll}
\hline & Before lockdown $(n=39)$ & After lockdown $(n=69)$ & $p$-value \\
\hline Age (years) (median (IQR) & $8.9(5.7-12.2)$ & $11.1(9.1-13.2)$ & $\mathbf{0 . 0 0 3}$ \\
Weight (kg) & 28 & 37.5 & $\mathbf{0 . 0 0 7}$ \\
Female gender & $18(46 \%)$ & $27(39 \%)$ & $\mathbf{0 . 0 4 6}$ \\
Distance between home and Robert- & $15(52 \%)$ & $53(77 \%)$ & $\mathbf{0 . 0 1 7}$ \\
$\quad$ Debré University Children Hospi- & & & \\
tal $>$ 5 km & $13(33 \%)$ & $10(15 \%)$ & $\mathbf{0 . 0 2 8}$ \\
Previous medical consultation: & $11(28 \%)$ & $9(15 \%)$ & 0.07 \\
Family doctor/general practitioner & $5(13 \%)$ & $2(3 \%)$ & 0.095 \\
$\quad$ Robert-Debré emergency room & $12(31 \%)$ & $36(52 \%)$ & $\mathbf{0 . 0 4 3}$ \\
Transfer from other hospital & & & \\
\hline
\end{tabular}

Bold font indicates statistical significance

\section{Clinical presentation}

The mean duration of symptoms was 2 days in both periods $(p=0.478)$ (Table 2). The number of patients that was admitted in our center after 3 or more days of symptoms was similar in both periods ( $26 \%$ before lockdown, $19 \%$ during lockdown, $p=0.466$ ).

The rate of complicated appendicitis was $85 \%$ before the lockdown and $74 \%$ during the lockdown $(p=0.235)$. Mean CRP levels and leukocyte count were similar between both periods.

\section{Surgery}

Laparoscopic appendectomy was performed for all children with uncomplicated appendicitis and complicated appendicitis with peritonitis. No conversions to laparotomy were required. Time to appendectomy was similar between both groups $(5.2 \mathrm{~h}$ before the lockdown, $6.4 \mathrm{~h}$ after the lockdown, $p=0.84)$. Regarding uncomplicated appendicitis, the sameday discharge was performed in $50 \%$ of the children in both periods $(p=0.99)$.

\section{Outcome}

The median length of hospital stay for acute appendicitis in children was 4 days before and after the lockdown $(p=0.51)$ (Table 3). During the lockdown, two children (3\%) required postoperative ICU stay: one child had both severe acute appendicitis with peritonitis and COVID-19 pneumonia, the second child had acute appendicitis with peritonitis and developed respiratory distress after postoperative extubation, due to acute pulmonary edema (COVID-19 negative).

After appendectomy, $14 \%$ of children developed an IAA, after a median delay of 8 days (IQR: 5-10 days). The prevalence of IAA and the delay between appendectomy and IAA was similar between both periods. Before the lockdown, 7 children (18\%) managed for acute appendicitis visited the

Table 2 Acute appendicitis: duration of symptoms, imaging and biological findings, disease form, time to appendectomy

\begin{tabular}{|c|c|c|c|}
\hline & Before lockdown $(n=39)$ & After lockdown $(n=69)$ & $p$-value \\
\hline $\begin{array}{l}\text { Duration of symptoms before admission (days) (median } \\
\text { (IQR)) }\end{array}$ & $2(1-3)$ & $2(1-2)$ & 0.478 \\
\hline Duration of symptoms $\geq 3$ days & $10(25 \%)$ & $13(19 \%)$ & 0.466 \\
\hline \multicolumn{4}{|l|}{ Imaging studies: } \\
\hline Abdominal ultrasound & $26(67 \%)$ & $48(70 \%)$ & 0.83 \\
\hline Abdominal CT-scan & $4(10 \%)$ & $13(19 \%)$ & 0.283 \\
\hline \multicolumn{4}{|l|}{ Disease form } \\
\hline Uncomplicated appendicitis & $6(15 \%)$ & $18(26 \%)$ & 0.235 \\
\hline Complicated with peritonitis & $30(77 \%)$ & $47(68 \%)$ & 0.382 \\
\hline Complicated with mass/abscess & $3(8 \%)$ & $4(6 \%)$ & 0.701 \\
\hline \multicolumn{4}{|l|}{ Biological findings at diagnosis } \\
\hline CRP (mg/L) (median (IQR)) & $56(21-140)$ & $45(14-94)$ & 0.24 \\
\hline Leukocyte count $\left(1 \times 10^{3} / \mathrm{mm}^{3}\right)($ median $(\mathrm{IQR}))$ & $16(13.1-19.4)$ & $15.3(12.3-30.3)$ & 0.89 \\
\hline Time to appendectomy (hours) (median (IQR)) & $5.2(3.3-11.8)$ & $6.4(3.3-9.8)$ & 0.84 \\
\hline
\end{tabular}


Table 3 Acute appendicitis: outcome, length of stay, and complications

\begin{tabular}{llll}
\hline & $\begin{array}{l}\text { Before lock- } \\
\text { down }(n=39)\end{array}$ & $\begin{array}{l}\text { After lock- } \\
\text { down }(n=69)\end{array}$ & $p$-value \\
\hline ICU stay required & $0(0 \%)$ & $2(3 \%)$ & 0.53 \\
$\begin{array}{l}\text { Length of stay (days) } \\
\text { Postoperative IAA }\end{array}$ & $4(3-6)$ & $4(3-5)$ & 0.51 \\
$\begin{array}{l}\text { Medically-treated } \\
\text { Surgically-treated }\end{array}$ & $4(11 \%)$ & $5(8 \%)$ & 0.99 \\
$\quad 1(3 \%)$ & $4(6 \%)$ & \\
$\quad$ drainage or laparos- & & $9 / 65(14 \%)$ & \\
$\begin{array}{l}\text { Delay between appen- } \\
\text { dectomy and IAA } \\
\quad \text { days) }\end{array}$ & $9(5.5-10)$ & $7(5-11)$ & 0.8 \\
$\begin{array}{l}\text { 30-day ER visit } \\
\text { 30-day readmission }\end{array}$ & $7(18 \%)$ & $8(12 \%)$ & 0.39 \\
\hline
\end{tabular}

ER in 30 days after discharge, whereas 8 children managed for acute appendicitis during the lockdown visited the ER in the 30 days after discharge $(12 \%, p=0.39)$. The 30 -day readmission rate was similar between both periods $(8 \%$ before lockdown vs. $6 \%$ during lockdown, $p=0.7$ ). Throughout the study period, none of the children managed conservatively for complicated appendicitis with mass/abscess developed recurrence of appendicitis and/or visited the ER within the 30 days after discharge.

\section{Acute appendicitis associated with COVID-19}

Before the lockdown, no child was diagnosed with COVID19. During the lockdown, 3 children (4\%) were diagnosed with COVID-19 and acute appendicitis, and 4 (6\%) patients had a history of suspected COVID-19 household contact.

One of these children (Patient 1) presented with associated respiratory signs and was tested positive for SARSCoV-2. The context of COVID-19 resulted in a delayed diagnosis of acute appendicitis, and a delayed surgical management as the child underwent laparoscopy $12 \mathrm{~h}$ after admission. Severe peritonitis with a perforated appendix was found, and the child required postoperative ICU stay, several lines of intravenous antibiotics, an IAA drainage on postoperative day 14 , and was discharged home 28 days after surgery. He visited the ER three times within 30 days after discharge for various complaints, including diffuse abdominal pain, shortness of breath, and asthenia. Upon biological and radiographic examinations, no underlying cause was found, apart from a persistent positive COVID-19 RT-PCR. Another child (Patient 2) with a suspected COVID-19 household contact had a positive RT-PCR result, despite presenting no respiratory symptoms at the time of acute appendicitis. She underwent laparoscopic appendectomy revealing peritonitis, and received a 3-day course of intravenous antibiotics. Her postoperative course was uneventful and she was discharged home on postoperative day 3 . She visited the ER once 17 days after discharge, complaining of headaches and odynophagia, revealing tonsillitis with a negative strep-test.

The 2 other children with suspected COVID-19 household contact had negative RT-PCR results, uncomplicated acute appendicitis and underwent laparoscopic appendectomy, with an uneventful postoperative course and no postoperative ER visits.

The third child (Patient 3) was diagnosed with COVID19 while being asymptomatic for COVID-19 and having no history of suspected COVID-19 household contact. He underwent laparoscopic appendectomy as an ambulatory surgery and had an uneventful postoperative course and no postoperative ER visits. This child was diagnosed with COVID-19 as a result of the implementation of systematic RT-PCR-testing of all patients that were admitted to the hospital starting on April 17th, 2020. Between April 17th and May 11th, 39 children admitted for acute appendicitis were systematically tested for 2019-nCOV, and 2(5\%) were found to be positive for COVID-19 (Patient 2 and 3).

\section{Discussion}

The restructuration of the healthcare system due to the COVID-19 pandemic resulted in a $77 \%$ increase in the number of patients managed for acute appendicitis in our pediatric surgery department during the lockdown. Despite this increase in workload, our study highlights that children were managed as effectively as before the lockdown. Moreover, refuting our hypothesis, we did not observe any difference between both periods in the delay before consultation, in the rate of complicated forms of acute appendicitis, in the length of stay or postoperative complications. We can conclude that the lockdown and restructuration of the healthcare system due to the COVID-19 pandemic did not result in collateral damage for children managed for acute appendicitis at our center.

The increase in the number of patients may be explained by the closure of general surgery departments in proximity hospitals, resulting in an increase in the number of patients referred to our center. We found that children managed for acute appendicitis at our center during the lockdown were older and were more likely to live more than $5 \mathrm{~km}$ away from our institution than children managed before the lockdown. This can possibly be explained by the fact that general surgery departments would usually manage these older patients and would not refer them to our pediatric tertiary surgery center before the lockdown. As a result, more than half of the patients managed during the lockdown had been 
transferred from other hospitals, underlying the role of specific centers in providing child care during this crisis.

In this context of COVID-19 pandemic, several authors have advocated for nonoperative management of uncomplicated acute appendicitis, in order to relieve healthcare systems and avoid potential exposure of healthcare professionals to SARS-CoV-2 during surgery [20,21]. Some surgeons have modified their practice to a predominantly conservative management of uncomplicated acute appendicitis in adults during the COVID-19 pandemic [22]. Conservative management of uncomplicated appendicitis in selected children has been successfully reported in several studies, and has been reported as associated with a lower number of disability days and lower appendicitis health-care costs [23]. However, these results remain controversial as $23 \%$ of these children require appendectomy at 1 year and up to $46 \%$ of within 5 years [23, 24]. Moreover, in these studies, only $19 \%$ of children with acute appendicitis were eligible to conservative treatment. Recently, an American center reported treating all children with nonoperative management during the peak of the pandemic, including $45.5 \%$ of children that were eventually discharged without appendectomy [25]. Of these, $78 \%$ did not meet previously published criteria for nonoperative management of appendicitis [25]. In our institution, we decided not to modify our practice, and all children with uncomplicated acute appendicitis underwent surgery according to our preexisting protocol. We believe that modifying our practice regarding management of uncomplicated appendicitis requires a strong standardized management, that should not be instituted in a time of healthcare crisis. Moreover, nonoperative management of uncomplicated appendicitis in children may result in an increase in length of stay and readmission, that should be avoided during this COVID19 pandemic [26, 27]. In the study from Kvasnovsky et al., initial nonoperative management resulted in an increase in length of stay for children eventually undergoing appendectomy for uncomplicated appendicitis, and medium to long-term follow-up is to date unavailable for patients who were treated nonoperatively [25]. Finally, most surgeons that modified their practice to a conservative management due to COVID-19 indicated they would be returning to operative management after the pandemic [22]. Maintaining the sameday discharge appendectomy in uncomplicated appendicitis remained a safe option during this pandemic [28].

For children with a known positive COVID-19 status, conservative treatment of appendicitis can also be discussed, as recent studies have reported high rates of postoperative mortality or pulmonary complications in COVID-19 adults undergoing surgery [29, 30]. However, these results are challenging to translate to pediatric appendicitis, as the main risk factors for mortality or pulmonary complications identified in these studies were age $>70$ years, an ASA score $>3-4$, malignant disease or major surgery $[29,30]$. To date, no study has demonstrated an increase in complications or death after surgery in COVID-19 children. Moreover, no study has compared outcomes after surgical and conservative treatment of appendicitis in children with COVID-19, and it remains unknown if conservative treatment of appendicitis is safer than surgical treatment in children with COVID-19.

It has been suggested that laparoscopy increases the risk of SARS-CoV-2 transmission through the theoretical possibility of viral transmission from aerosolization of tissue and peritoneal fluid during surgery, dissuading some teams from performing laparoscopy during the pandemic [31, 32]. We maintained laparoscopic approach for appendectomy, as several randomized controlled trials have demonstrated that laparoscopy is associated to improved outcomes compared to open surgery in children with appendicitis [33-36]. During this crisis, we aimed to provide optimal management of surgical emergencies in children. Nonetheless, we implemented precautions in order to reduce the risk of SARS-CoV-2 transmission during surgery. It is still controversial whether peritoneal fluid of COVID-19 patients contain SARS-CoV-2, as only few studies report analysis of peritoneal fluid with discordant results [37, 38]. Similarly, SARS-CoV-2 has never been identified in surgical smoke [39].

During the lockdown, children managed for acute appendicitis were less likely to have consulted a general practitioner before coming to the emergency room, compared to before the lockdown. This could be due to the shortage in personal protective equipment, rendering general practitioners less available and less likely to receive children, that were stigmatized as being the "link in the transmission chain" [40]. Moreover, parents might have felt more comfortable in consulting at a pediatric hospital than a general practitioner, feeling that they were less likely to encounter the virus and that the pediatric ER would provide optimal care for their child. A previous study from China highlighted the changes in children's healthcare visits during the COVID-19 pandemic [41].

Although we expected parents to be reluctant to breaking the "stay-at-home" recommendation, the lockdown had no impact on the median duration of symptoms before consulting the ER. Accordingly, there was no difference in rates of complicated forms of acute appendicitis before and during the lockdown. Despite the increase in the number of children managed for acute appendicitis during this pandemic, time to appendectomy was similar throughout the study period, owing to an effective ongoing pediatric surgical call. Moreover, time to appendectomy remained lower than reported in previous studies [42]. Finally, we found no difference in outcome in terms of length of hospital stay and development of IAA between both periods, suggesting management of acute appendicitis was as efficient throughout the study period. 
Although there was no overall collateral damage on this population of children diagnosed with acute appendicitis, our cohort includes one child that qualifies as having suffered from some collateral damage, possibly related to the COVID19 pandemic. Indeed, Patient 1 with a context of suspected COVID-19 household contact stayed home for 4 days after being diagnosed with suspected COVID-19 with predominant gastrointestinal symptoms by a general practitioner. After arrival at our institution, the misleading associated COVID-19 infection resulted in additional delay in diagnosis and time to appendectomy. This overall delay in diagnosis of appendicitis due to the associated COVID-19 infection resulted in a severe form of complicated appendicitis and a complicated postoperative course requiring IAA drainage. Moreover, he visited the ER several times after discharge, for possible COVID-19 residual symptoms. The other child that was diagnosed with asymptomatic RT-PCR-positive COVID-19 associated with acute appendicitis visited the ER 17 days after discharge for symptoms related to COVID-19.

\section{Limitations}

We acknowledge that this study has limitations related to its retrospective nature. We chose to compare the lockdown period to the period immediately preceding the lockdown instead of comparing to the previous year, in order to highlight differences due to the lockdown, and avoid bias such as different ER, anesthesia, and surgical teams. We do not believe that seasonal variation may have a role in this increase in incidence of appendicitis as studies show an increase during the summer months and low incidence from March to May [43, 44]. Finally, the change in testing strategy during the study period precludes the true assessment of rates of COVID-19 positive children treated for acute appendicitis throughout the whole study period. Indeed, due to equipment shortage, we could not initially perform systematic RT-PCR for all children upon admission, and only children with a history of household COVID-19 infection or respiratory symptoms were tested. Another limitation to our study is our inability to assess any potential collateral damage made to medical personnel in pursuing our preexisting surgical management of acute appendicitis. Although we have no known cases of COVID-19 contamination of medical personnel due to exposure during appendectomy of a child with acute appendicitis during the lockdown, this would have been challenging to assess during this healthcare crisis.

\section{Conclusion}

Despite a significant increase in the number of children with acute appendicitis treated at our hospital during this COVID19 pandemic, management and outcome of these children remained similar before and during the lockdown. Although our pediatric center was strongly affected by the COVID-19 pandemic, maintaining our prior practice strategies for acute appendicitis associated to new protocols for reducing SARS$\mathrm{CoV}-2$ exposure avoided the occurrence of collateral damage for children managed for acute appendicitis.

Funding No external funding for this manuscript.

\section{Compliance with ethical standards}

Conflicts of Interest The authors have no conflicts of interest relevant to this article to disclose.

\section{References}

1. Low TY, So JBY, Madhavan KK, Hartman M (2020) Restructuring the surgical service during the COVID-19 pandemic: experience from a tertiary institution in Singapore. Br J Surg. https:// doi.org/10.1002/bjs.11701

2. Ceylan Z (2020) Estimation of COVID-19 prevalence in Italy, Spain, and France. Sci Total Environ 729:138817. https://doi. org/10.1016/j.scitotenv.2020.138817

3. Salje H, Tran Kiem C, Lefrancq N, Courtejoie N, Bosetti P, Paireau J et al (2020) Estimating the burden of SARS-CoV-2 in France. Science. https://doi.org/10.1126/science.abc3517

4. Wulkan ML (2020) Pediatric surgery in the time of COVID-19. J Laparoendosc Adv Surg Tech A 30:355. https://doi.org/10.1089/ lap.2020.29031.mlw

5. Zhou Y, Xu H, Li L, Ren X (2020) Management for patients with pediatric surgical disease during the COVID-19 epidemic. Pediatr Surg Int 36:751-752. https://doi.org/10.1007/s00383-020-04656 $-6$

6. L'hôpital Robert-Debré, AP-HP, célèbre ses 30 ans. 14/05/2018 n.d. https://www.aphp.fr/contenu/lhopital-robert-debre-ap-hpcelebre-ses-30-ans.

7. Kulik DM, Uleryk EM, Maguire JL (2013) Does this child have appendicitis? A systematic review of clinical prediction rules for children with acute abdominal pain. J Clin Epidemiol 66:95-104. https://doi.org/10.1016/j.jclinepi.2012.09.004

8. Somekh I, Somech R, Pettoello-Mantovani M, Somekh E (2020) Changes in routine pediatric practice in light of COVID-19. J Pediatr. https://doi.org/10.1016/j.jpeds.2020.05.053

9. CCI Paris Ile-De-France. Paris Region Facts \& Figures 2020 2020. https://www.cci-paris-idf.fr/sites/default/files/crocis/wysiw yg/PRFF2020_Population.pdf

10. Snapiri O, Rosenberg Danziger C, Krause I, Kravarusic D, Yulevich A, Balla U et al (2020) Delayed diagnosis of pediatric appendicitis during the COVID-19 pandemic. Acta Paediatr. https ://doi.org/10.1111/apa.15376

11. Tullie L, Ford K, Bisharat M, Watson T, Thakkar H, Mullassery D et al (2020) Gastrointestinal features in children with COVID-19: an observation of varied presentation in eight children. Lancet Child Adolesc Heal. https://doi.org/10.1016/S2352 $-4642(20) 30165-6$

12. Toubiana J, Poirault C, Corsia A, Bajolle F, Fourgeaud J, Angoulvant $\mathrm{F}$ et al (2020) Kawasaki-like multisystem inflammatory syndrome in children during the covid-19 pandemic in Paris, France: prospective observational study. BMJ 369:m2094. https://doi. org/10.1136/bmj.m2094 
13. Zachariah P, Johnson CL, Halabi KC, Ahn D, Sen AI, Fischer A et al (2019) Epidemiology, clinical features, and disease severity in patients with coronavirus disease 2019 (COVID-19) in a children's hospital in New York City, New York. JAMA Pediatr 2020:e202430. https://doi.org/10.1001/jamapediatrics.2020.2430

14. Richardsen I, Schöb DS, Ulmer TF, Steinau G, Neumann UP, Klink CD et al (2016) Etiology of appendicitis in children: the role of bacterial and viral pathogens. J Invest Surg 29:74-79. https:// doi.org/10.3109/08941939.2015.1065300

15. Parmentier B, Berrebi D, Peycelon M, Doit C, El GA, Bonnard A (2016) Failure of first-line antibiotics in nonoperative management of appendiceal mass, toward a second-line instead of surgery? Eur J Pediatr Surg 26:267-272. https://doi.org/10.1055/s-0035-15515 71

16. Cook TM, El-Boghdadly K, McGuire B, McNarry AF, Patel A, Higgs A (2020) Consensus guidelines for managing the airway in patients with COVID-19: Guidelines from the Difficult Airway Society, the Association of Anaesthetists the Intensive Care Society, the Faculty of Intensive Care Medicine and the Royal College of Anaesthetists. Anaesthesia 75:785-799. https://doi. org/10.1111/anae. 15054

17. Kangas-Dick AW, Swearingen B, Wan E, Chawla K, Wiesel O (2020) Safe extubation during the COVID-19 pandemic. Respir Med 170:106038. https://doi.org/10.1016/j.rmed.2020.106038

18. Wax RS, Christian MD (2020) Practical recommendations for critical care and anesthesiology teams caring for novel coronavirus (2019-nCoV) patients. Can J Anaesth 67:568-576. https:// doi.org/10.1007/s12630-020-01591-X

19. Forrester JD, Nassar AK, Maggio PM, Hawn MT (2020) Precautions for operating room team members during the COVID19 pandemic. J Am Coll Surg 230:1098-1101. https://doi. org/10.1016/j.jamcollsurg.2020.03.030

20. Collard M, Lakkis Z, Loriau J, Mege D, Sabbagh C, Lefevre JH et al (2020) Antibiotics alone as an alternative to appendectomy for uncomplicated acute appendicitis in adults: changes in treatment modalities related to the COVID-19 health crisis. J Visc Surg. https://doi.org/10.1016/j.jviscsurg.2020.04.014

21. Polites SF, Azarow KS (2020) Perspectives on pediatric appendicitis and appendectomy during the severe acute respiratory syndrome coronavirus 2 pandemic. J Laparoendosc Adv Surg Tech A 30:356-357. https://doi.org/10.1089/lap.2020.0197

22. Kelly ME, Murphy E, Bolger JC, Cahill RA (2020) COVID19 and the treatment of acute appendicitis in Ireland: a new era or short-term pivot? Colorectal Dis. https://doi.org/10.1111/ codi. 15141

23. Minneci PC, Hade EM, Lawrence AE, Sebastião YV, Saito JM, Mak GZ et al (2020) Association of nonoperative management using antibiotic therapy vs laparoscopic appendectomy with treatment success and disability days in children with uncomplicated appendicitis. JAMA J Am Med Assoc. https://doi.org/10.1001/ jama.2020.10888

24. Patkova B, Svenningsson A, Almström M, Eaton S, Wester T, Svensson JF (2020) Nonoperative treatment versus appendectomy for acute nonperforated appendicitis in children: five-year follow up of a randomized controlled pilot trial. Ann Surg 271:1030 1035. https://doi.org/10.1097/SLA.0000000000003646

25. Kvasnovsky CL, Shi Y, Rich BS, Glick RD, Soffer SZ, Lipskar AM et al (2020) Limiting hospital resources for acute appendicitis in children: Lessons learned from the US epicenter of the COVID-19 pandemic. J Pediatr Surg. https://doi.org/10.1016/j. jpedsurg.2020.06.024

26. Kessler U, Mosbahi S, Walker B, Hau EM, Cotton M, Peiry B et al (2017) Conservative treatment versus surgery for uncomplicated appendicitis in children: a systematic review and meta-analysis. Arch Dis Child 102:1118-1124. https://doi.org/10.1136/archd ischild-2017-313127
27. Huang L, Yin Y, Yang L, Wang C, Li Y, Zhou Z (2017) Comparison of antibiotic therapy and appendectomy for acute uncomplicated appendicitis in children: a meta-analysis. JAMA Pediatr 171:426-434. https://doi.org/10.1001/jamapediatrics.2017.0057

28. Cairo SB, Raval MV, Browne M, Meyers H, Rothstein DH (2017) Association of same-day discharge with hospital readmission after appendectomy in pediatric patients. JAMA Surg 152:1106-1112. https://doi.org/10.1001/jamasurg.2017.2221

29. Nepogodiev D, Bhangu A, Glasbey JC, Li E, Omar OM, Simoes JF et al (2020) Mortality and pulmonary complications in patients undergoing surgery with perioperative SARS-CoV-2 infection: an international cohort study. Lancet 396:27-38. https://doi. org/10.1016/S0140-6736(20)31182-X

30. Doglietto F, Vezzoli M, Gheza F, Lussardi GL, Domenicucci M, Vecchiarelli L et al (2019) Factors associated with surgical mortality and complications among patients with and without coronavirus disease 2019 (COVID-19) in Italy. JAMA Surg 2020:155. https://doi.org/10.1001/jamasurg.2020.2713

31. Veziant J, Bourdel N, Slim K (2020) Risks of viral contamination in healthcare professionals during laparoscopy in the Covid-19 pandemic. J Visc Surg. https://doi.org/10.1016/j.jvisc surg.2020.04.010

32. Francis N, Dort J, Cho E, Feldman L, Keller D, Lim R et al (2020) SAGES and EAES recommendations for minimally invasive surgery during COVID-19 pandemic. Surg Endosc 34:2327-2331. https://doi.org/10.1007/s00464-020-07565-w

33. Lintula H, Kokki H, Vanamo K (2001) Single-blind randomized clinical trial of laparoscopic versus open appendicectomy in children. Br J Surg 88:510-514. https://doi.org/10.104 6/j.1365-2168.2001.01723.x

34. Jaschinski T, Mosch CG, Eikermann M, Neugebauer EAM, Sauerland S (2018) Laparoscopic versus open surgery for suspected appendicitis. Cochrane Database Syst Rev. https://doi. org/10.1002/14651858.CD001546.pub4

35. Yu G, Han A, Wang W (2016) Comparison of laparoscopic appendectomy with open appendectomy in treating children with appendicitis. Pakistan J Med Sci 32:299-304. https://doi.org/10.12669/ pjms.322.9082

36. Low ZX, Bonney GK, So JBY, Loh DL, Ng JJ (2019) Laparoscopic versus open appendectomy in pediatric patients with complicated appendicitis: a meta-analysis. Surg Endosc 33:40664077. https://doi.org/10.1007/s00464-019-06709-x

37. Ngaserin SHN, Koh FH, Ong BC, Chew MH (2020) COVID-19 not detected in peritoneal fluid: a case of laparoscopic appendicectomy for acute appendicitis in a COVID-19-infected patient. Langenbeck's Arch Surg 405:353-355. https://doi.org/10.1007/ s00423-020-01891-2

38. Flemming S, Hankir M, Hering I, Meybohm P, Krone M, Weissbrich B et al (2020) Abdominal fluid samples (negative for SARSCoV-2) from a critically unwell patient with respiratory COVID19. Br J Surg. https://doi.org/10.1002/bjs.11713

39. Mintz Y, Arezzo A, Boni L, Baldari L, Cassinotti E, Brodie R et al (2020) The risk of COVID-19 transmission by laparoscopic smoke may be lower than for laparotomy: a narrative review. Surg Endosc. https://doi.org/10.1007/s00464-020-07652-y

40. Kelvin AA, Halperin S (2020) COVID-19 in children: the link in the transmission chain. Lancet Infect Dis 20:633-634. https://doi. org/10.1016/S1473-3099(20)30236-X

41. Li H, Yu G, Duan H, Fu J, Shu Q (2020) Changes in children's healthcare visits during COVID-19 pandemic in Hangzhou, China. J Pediatr. https://doi.org/10.1016/j.jpeds.2020.05.013

42. Serres SK, Cameron DB, Glass CC, Graham DA, Zurakowski D, Karki M et al (2017) Time to appendectomy and risk of complicated appendicitis and adverse outcomes in children. JAMA Pediatr 171:740-746. https://doi.org/10.1001/jamapediat rics. 2017.0885 
43. Rautava L, Rautava P, Sipilä J, Kytö V (2018) Occurrence and treatment of pediatric appendicitis in Finland 2004-2014. J Surg Res 232:33-38. https://doi.org/10.1016/j.jss.2018.06.010

44. Hsu Y-J, Fu Y-W, Chin T (2019) Seasonal variations in the occurrence of acute appendicitis and their relationship with the presence of fecaliths in children. BMC Pediatr 19:443. https://doi. org/10.1186/s12887-019-1824-9
Publisher's Note Springer Nature remains neutral with regard to jurisdictional claims in published maps and institutional affiliations. 